\title{
Urban design for food systems
}

\author{
June Komisar ${ }^{1}$. Joe Nasr ${ }^{2}$
}

Published online: 14 June 2019

(c) Springer Nature Limited 2019

The food system is increasingly acknowledged to be a basic urban system, just as much as transportation and the water supply are urban systems (Steel 2008). The interactions between food systems and other basic urban systems (historically and currently) are also becoming more evident and better understood. This is overturning assumptions that the food system is a largely rural system of flows managed by local, national, and global actors through agricultural policy and expertise, supplying urban areas with their food needs through private entrepreneurs with little input or shaping by urban stakeholders. In contrast to this view, the role of cities and their surrounding regions as a key locus of action is now seen as fundamental for understanding and intervening in the food system (Forster and Escudero 2014; Blay-Palmer et al. 2015). At the same time, the stability of the food supply to cities and the secure access of citizens to adequate nourishment is becoming a cause for growing concern. As a result, disciplines that deal with the design of urban settlements have started to recognize that they can and should play a wide range of roles in shaping the urban food system, particularly by addressing its connections to the material environments on which they normally work: the home, the workplace, the street, the public space, and the public institution (Pothukuchi and Kaufman 2000; Bohn and Viljoen 2014; Gorgolewski et al. 2016; Nasr et al. 2014; Cabannes and Marocchino 2018).

The focus of this special issue of Urban Design International is thus the food system, recognizing that this is a key component of the urban environment-both built and unbuilt—which is shaped by many participants as well as

June Komisar

jkomisar@ryerson.ca

Joe Nasr

jnasr@ryerson.ca

1 Department of Architectural Science, FEAS, Ryerson University, 350 Victoria Street, Toronto, ON M5B 2K3, Canada

2 Centre for Studies in Food Security, Ryerson University, 350 Victoria Street, Toronto, ON M5B 2K3, Canada structural factors. In the past decade, a number of publications as well as projects have shone a light on the role of design relative to various aspects of urban food systems, in particular, urban agriculture (Viljoen et al. 2005; de la Salle and Holland 2010; Gorgolewski et al. 2011; Nasr and Komisar 2012). The broader food system approach enables the inclusion in this issue of articles that span a range of topics, from growing, to processing, distributing, marketing, and managing the waste stream. The shaping of the urban environment through the integration of many disciplines, from landscape design to transportation planning, includes the food system as a key component.

We were particularly interested in including papers that deal with multiple aspects of food systems, and how these aspects interact with each other, with other urban systems, and with other aspects of the urban realm. Adopting a systems approach to looking at food and connecting this to urban design is at the core of the issue. This approach highlights the importance of scale-the six papers included here do not simply consider buildings and their components, but rather connect these, through a food system approach, to community, neighborhood, the city, or even the region. In addition, the focus here is on urban design, not policy; the capacity to shape the city as a physical space and the material needs related to the manifestation of the food system in the urban realm is central to our interests here.

In the initial call for papers, we identified a number of ways in which food systems intersect with core urban design issues. These include:

- Typologies of designing for food system components

- Food systems as part of a participatory design process

- Integration of food-focused facilities in adaptive reuse strategies

- Food hubs as catalysts for community development

- Public green spaces as productive spaces

- Productive landscape approaches

- Designing for urban agriculture

- Community composting and other forms of integrating waste management in the city 
- Reconceiving schools and other educational facilities as food knowledge centres.

This initial call generated submissions that dealt with nine countries. At the end, six papers were accepted for inclusion in this issue. The focus of the research, the context of the cases analyzed, the food system components dealt with, the background of the authors themselves-all these were as diverse as could have been hoped for when the call was announced. A brief synopsis of the six papers will give a sense of this wide range.

The first paper by Salvador offers a historical/geographical analysis of the food supply system of a city (Lisbon). Building on this specific history and geography, she identifies key traces of the past food system within the city of today and how these traces have changed function and meaning (if any). This leads her to a discussion of current actors in the local food system, focusing on their actions on particular places within the current urban context. Her paper thus melds history of food and place with an analysis of food and place initiatives today-showing the usefulness of a 'foodscape' lens to historical understanding as well as contemporary reading of a city.

Simon-Rojo's paper focuses on advocates for change in the dominant food system of a city (Madrid) through changes in practices-namely the adoption and adaptation of ecological principles (which are typically used in rural contexts) to urban environments, combined with the social justice movements that are already present in many cities. After setting the stage of such an analysis at the metropolitan scale, she uses as a case study a particular neighborhoodone that is quite dense and with challenging socioeconomic conditions. She shows how a fine-grained reading of a neighborhood can use spatial design principles derived from the analytical lens that agroecology provides.

The paper written by Jones and Franck focuses on the relation between building types and urban contexts and how food can lead to a reinvention of such types as neighborhoods change over time. They consider how the adaptive reuse of former industrial areas are transforming some of this existing infrastructure into elements of the food system, serving as sites for emerging businesses at different points of the food supply chain, from production to marketing. Using six case studies from four older US cities, they show how basic assumptions about where food fits in a city are being upended through adaptive reuse. They also show that the type of building being adapted, the context where such buildings are located, and the process through which the adaptation takes place (including the impacts of the regulatory framework), all vary dramatically.

De la Salle focuses in her paper on one basic feature of the urban fabric, namely the street system, developing a systematic analysis of street types and features as they relate to food-related activities, using a number of examples, most from Western Canadian cities and towns. Going further, the paper adopts a normative stand, making the claim for the need to recognize what makes "great food streets", building on Allan Jacobs' classic book. This stand is explicitly a reaction to the way people, places and food systems have been separated from each other. At the core of her argument is that the renewed interest by urban designers and planners in the quality of the street as a public realm has not placed food as a central element that contributes to this quality of streets.

Swai maintains a focus on the place of food in streets, but uses a fine-grained examination of a particular case- downtown Dar es Salaam-to undertake a multifaceted analysis of a number of dimensions of the place (and time) of food in streets. He shows that this presence (particularly through street foods) can be instrumental in the way streets work. This paper connects architectural dynamics, food system operations and sustainable livelihood strategies in an innovative analysis combining mapping, sketching, interviewing and measuring. This analysis leads ultimately to suggestions for recognizing the multiple roles that a particular segment of an informal economy can play-not only in terms of livelihood and food security, but also personal safety and urban development.

The last paper by Miedema differs from the other papers in this special issue. It represents a practitioner's grand vision for what a holistic, integrated, locally based food system could look like. It uses a specific neighborhood in the mid-sized Canadian city of London, Ontario, to ground this hypothetical approach to particular features of that neighborhood. She chooses a particular theoretical framework, the Transition Town principles articulated by Rob Hopkins, to outline step by step how a transferable strategy for a "cohesive infrastructure for a local food system" can be developed. The paper concludes by starting to consider what applying such a lens to an urban context can imply for urban design.

Some themes emerge across the different papers.

- A historical and geographical understanding of existing and potential conditions of food in cities needs to be integrated into urban design research.

- A systems approach to food in cities is relevant for understanding the place of food and its relation to other urban systems.

- Focussing on actors in food systems as well as urban design is necessary for a comprehension of the place of food in cities, and building on that, for the design of appropriate food-system interventions.

- Food-system analysis can be effectively combined with common analytical tools in urban design, such as the focus on basic urban elements like streets, the use of typomorphology, etc. 
- Normative claims for designing "good" city form (and for "great" streets) can be appropriately applied to food systems.

- Fine-grained analysis of the relation between food systems and physical context in cities is needed to enable effective urban design for food systems.

In recent years, food system thinking is increasingly recognized as a key factor for understanding a wide range of food issues as well as to develop and implement appropriate responses to these issues. Building on the application of system thinking to food challenges, food-system tools are gradually being developed. Moreover, food system thinking is evolving in relation to urban contexts, from the aforementioned city-region food systems to continuous productive urban landscapes to agrarian urbanism to urban agroecology. These various conceptual frameworks and accompanying sets of tools need to be integrated into urban design theory and practice which, so far, have remained rather immune to these burgeoning approaches.

If such integration were to take place in coming years, a few questions would be pertinent to readers of this journal. Where do urban designers fit into the food system picture? What can they contribute, in their daily practice, in terms of food system solutions? What lessons do the analyses offered by these six papers and the array of challenges that they identify provide urban designers? This thematic issue seeks to show urban design thinkers and practitioners that they belong around the food-system table.

\section{References}

Blay-Palmer, A., H. Renting, and M. Dubbeling. 2015. City-Region Food Systems: A Literature Review. Leusden: RUAF Foundation.
Bohn, K., and A. Viljoen (eds.). 2014. Second Nature Urban Agriculture-Designing Productive Cities. London and New York: Routledge.

Cabannes, Y., and C. Marocchino (eds.). 2018. Integrating Food into Urban Planning. London: UCL Press.

de la Salle, J., and M. Holland (eds.). 2010. Agricultural Urbanism: Handbook for Building Sustainable Food \& Agriculture Systems in 21st Century Cities. Winnipeg: Green Frigate Books.

Forster, T. and A. Getz Escudero. 2014. City Regions as Landscapes for People, Food and Nature. Washington, DC: EcoAgriculture Partners, on behalf of the Landscapes for People, Food and Nature Initiative.

Gorgolewski, M., J. Komisar, and J. Nasr. 2011. Carrot City: Creating Places for Urban Agriculture. New York: Monacelli Press.

Gorgolewski, M., J. Komisar, and J. Nasr. 2016. Resilient city = carrot city: Urban agriculture theories and designs. In Integrated Urban Agriculture: Precedents, Practices, Prospects, ed. R.L. France, 255-277. Faringdon: Green Frigate Books.

Nasr, J., and J. Komisar. 2012. Integration of food and agriculture into urban planning and design practices. In Sustainable Food Planning: Evolving Theory and Practice, ed. A. Viljoen and $\mathrm{H}$. Wiskerke, 45-56. Wageningen: Wageningen Academic Publishers.

Nasr, J., J. Komisar, and M. Gorgolewski. 2014. Urban agriculture as ordinary urban practice: Trends and lessons. In Second Nature Urban Agriculture-Designing Productive Cities, ed. K. Bohn and A. Viljoen, 24-31. London: Routledge.

Pothukuchi, K., and J. Kaufman. 2000. The food system: A stranger to the planning field. Journal of the American Planning Association 66 (2): 112-124.

Steel, C. 2008. Hungry City: How Food Shapes our Lives. London: Chatto \& Windus.

Viljoen, A., K. Bohn, and J. Howe (eds.). 2005. CPULs-Continuous Productive Urban Landscapes: Designing Urban Agriculture for Sustainable Cities. New York: Architectural Press/Elsevier.

Publisher's Note Springer Nature remains neutral with regard to jurisdictional claims in published maps and institutional affiliations. 